JMI Vol. 42 No. 2, Desember 2020

METAL INDONESIA

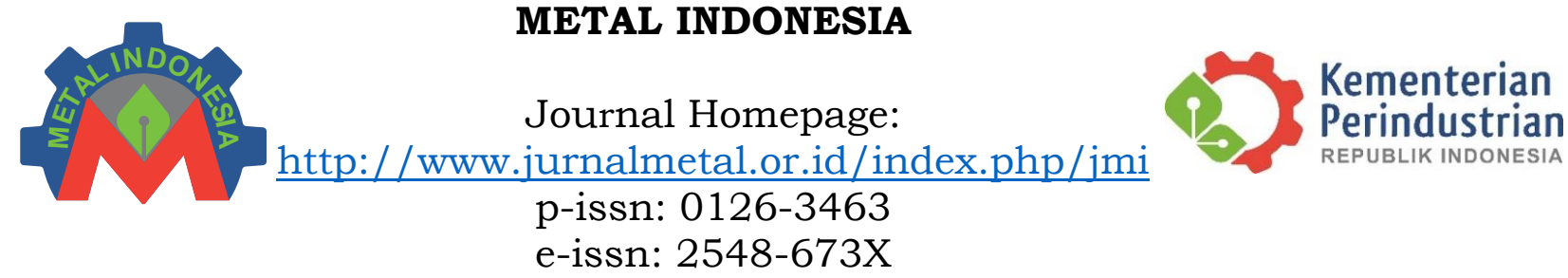

\title{
AN ELECTRIC DC MOTOR CONTROL SYSTEM WITH GECKODRIVE320X DRIVER MODULE
}

\author{
Agus Hananto $^{1 *}$, Rachmad Hartono ${ }^{2}$, Ahid Nuristinah ${ }^{3}$ \\ ${ }^{1}$ Studies Magister of Mechanical Engineering Institute Technology Bandung \\ ${ }^{2}$ Faculty Mechanical Engineering of Pasundan University \\ ${ }^{3}$ Badan Pusat Statistik Kota Bandung \\ E-mail : agus_hananto@yahoo.com,gushananto@kemenperin.go.id
}

\begin{abstract}
This research shows an example to make a servo motor which consists of three main components, a DC motor, a control circuit, and a closed feedback system. A rotary encoder is used as a closed feedback system by using Geckodrive $320 \mathrm{X}$ as a control circuit for controlling DC electric motors as the main components. The results showed that Geckodrive320X can be used to control a DC electric motor as a servo motor. The number of turns of the DC motor shaft depends on the condition of switches SW2 and SW3, achieved by giving four pulses to the Geckodrive320X. The maximum speed able to be controlled by Geckodrive $320 \mathrm{X}$ is $540 \mathrm{rpm}$, and the deviation maximum of the slider positioning is $0.01 \mathrm{~mm}$ under the conditions of multipliers of 5 and 10.
\end{abstract}

Keywords: Geckodrive320X, rotary encoder, multiplier, pulses

\section{INTRODUCTION}

In industry 4.0, control systems currently have an important role in the development of science and technology. The role of control systems covers all fields of industry, including manufacturing industries such as assembly parts, scanning parts, engine parts, processes in the aircraft industry, spacecraft, and others- etc. One of the controlling equipment in the manufacturing industry is a servo motor. Servo motors are rotary actuator devices that are integrated into a closed feedback control system (Murphy et al. 1987). The main components of servo motors are DC motors, control circuits, and closed feedback control systems. The Pulse Width Modulation (PWM) is used on setting the servo motor, the direction, and the speed of the rotation.

One of the main components of a servo motor that can be utilized if damage occurs is a DC electric motor. DC electric motor is an electric motor that requires a direct current voltage input on the magnetic field coil to be converted into mechanical motion energy. The stationary magnetic field coil is the stator while the rotating part or the anchor coil is the rotor (Lopatinsky et al. 2006). DC electric motors can be adjusted in speed, and direction of rotation, and the number of revolutions by certain methods.

A great deal of research has been conducted to control DC motors, but few experiments don't have carried out to find the accuracy level of DC motor after controlled. (Kurnia, Oetomo, and Sitepu 2016) has conducted the design and manufacture of a DC servo motor control interface with a microcontroller and octave software, the result in this research that the DC servo motor can be controlled by software interface. (Raditya, Kartanadi, and Linggarjati 2011) has also designed a DC servo motor controller using microcontroller Atmega85. The purpose of this 
study is to implement one way to control a DC motor to become a general servo motor by using the GeckoDrive320X driver as a control module.

\section{RESEARCH METODOLOGY The Control System}

The basic scheme of this DC electric motor controller system consists of the Geckodrive320x driver with a microcontroller, a DC electric motor, and an encoder. The microcontroller is connected to the computer. The function of the microcontroller is to determine the condition of the DIR input Pin, to determine the direction of rotation by a number of pulses at the CLOCK input Pin, and the determine the rotational speed and number of rotations of the DC motor (Dharmawan 2017). The hole in the encoder shaft is connected to the DC motor shaft and the encoder output is connected to GeckoDrive $320 \mathrm{X}$ so that the encoder can provide information to GeckoDrive320X about the number of rotations of the DC motor shaft. Data related to the servo motor control will be sent from the computer interface to the microcontroller (Zhou 2008). Figure 1 shows the schematic control of the DC motor.

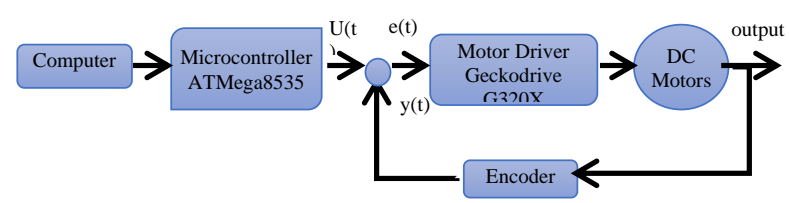

Figure 1. DC motor control schematic

The computer has the functions of sending data related to the rotation direction, rotational speed, and the number of revolutions of the DC motor to the microcontroller. The data is typed into a text-box of a visual basic application in the form of two numbers separated by a space. The first number is the direction data and the number of turns, while the second number is the speed of servo motor rotation. The data is entered into the microcontroller by pressing the SEND button. Data from the computer is sent to the microcontroller using serial communication. Figure 2 below shows the application program window/text-box. The microcontroller has the function of translating the data received from the computer to digital form to be used as Geckodrive320X input data. The microcontroller is ATMega8535 microcontroller. Figure 3 shows the schematic of the output pin of ATMega8535 Microcontroller.

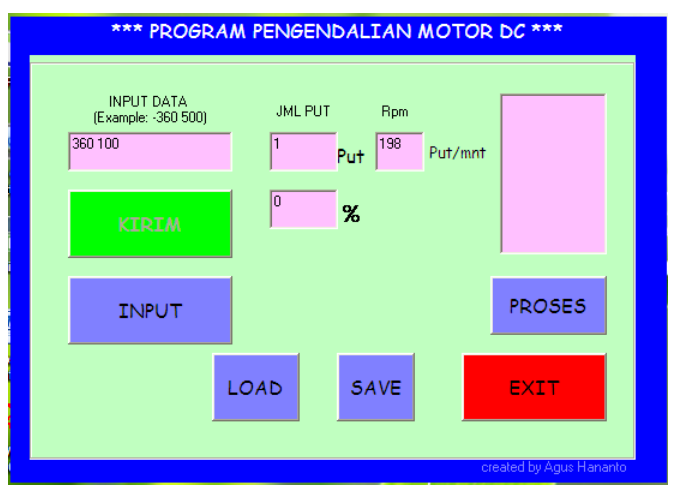

Figure 2. The DC motor control program application window for inputting the data

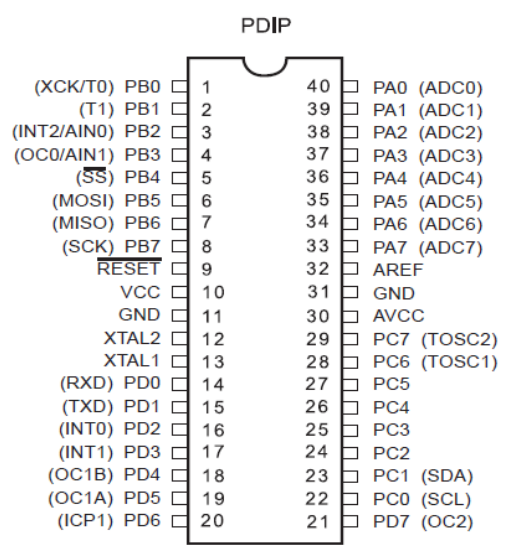

Figure 3. Pin out mikrokontroller atmega 8535 schematic

Geckodrive320X will execute the microcontroller input in the form of rotary motion and direction of rotation on the DC motor. Figure 4 below shows the geckodrive320X module.

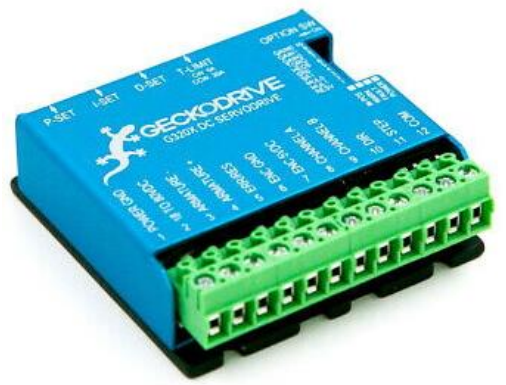

Figure 4. Geckodrive320X Module 
Geckodive320X has 12 functional Pins, see table 1. Geckodrive 320X is able to adjust the shaft position of the DC motor with positioning accuracy in accordance with the accuracy of the encoder attached to the DC motor shaft. Geckodrive320x working voltage specifications are 18 volts to 80 volts with a maximum electric current of 20 amperes. Geckodrive $320 X$ has 10 option switches, which can be used to;

- Determine the control pulse multiplier factor that entered the Geckodrive320X as a mean to detect the error limit of the DC motor shaft position.

- Determine the type of encoder.

- Determine the maximum current limit.

- Determine the multiplier factor for the PID constant.

- Geckodrive320X is also equipped with a potentiometer to adjust the PID constant value. Figure 5 below shows Geckodrive320X schematic (Faruq 2008).

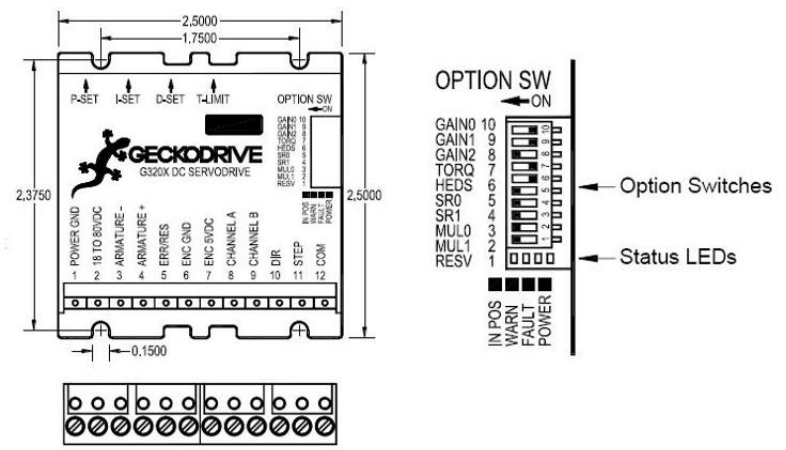

Figure 5. Geckodrive320X schematic

The encoder has the functions of measuring the position of the motor shaft (Widiyanto, Sumbodo, and Al Janan 2012). The encoder has three output pins, namely; output A, output B and output Z. Output A and output B give a certain number of pulses each time the encoder shaft rotates. The number of pulses of output $A$ and output $\mathrm{B}$ has a $90^{\circ}$ phase difference. Output $Z$ will issue one pulse per rotation of the encoder shaft. Figure 6 shows type of encoder used in this study.
Table 1. Geckodrive320X Functional Pins

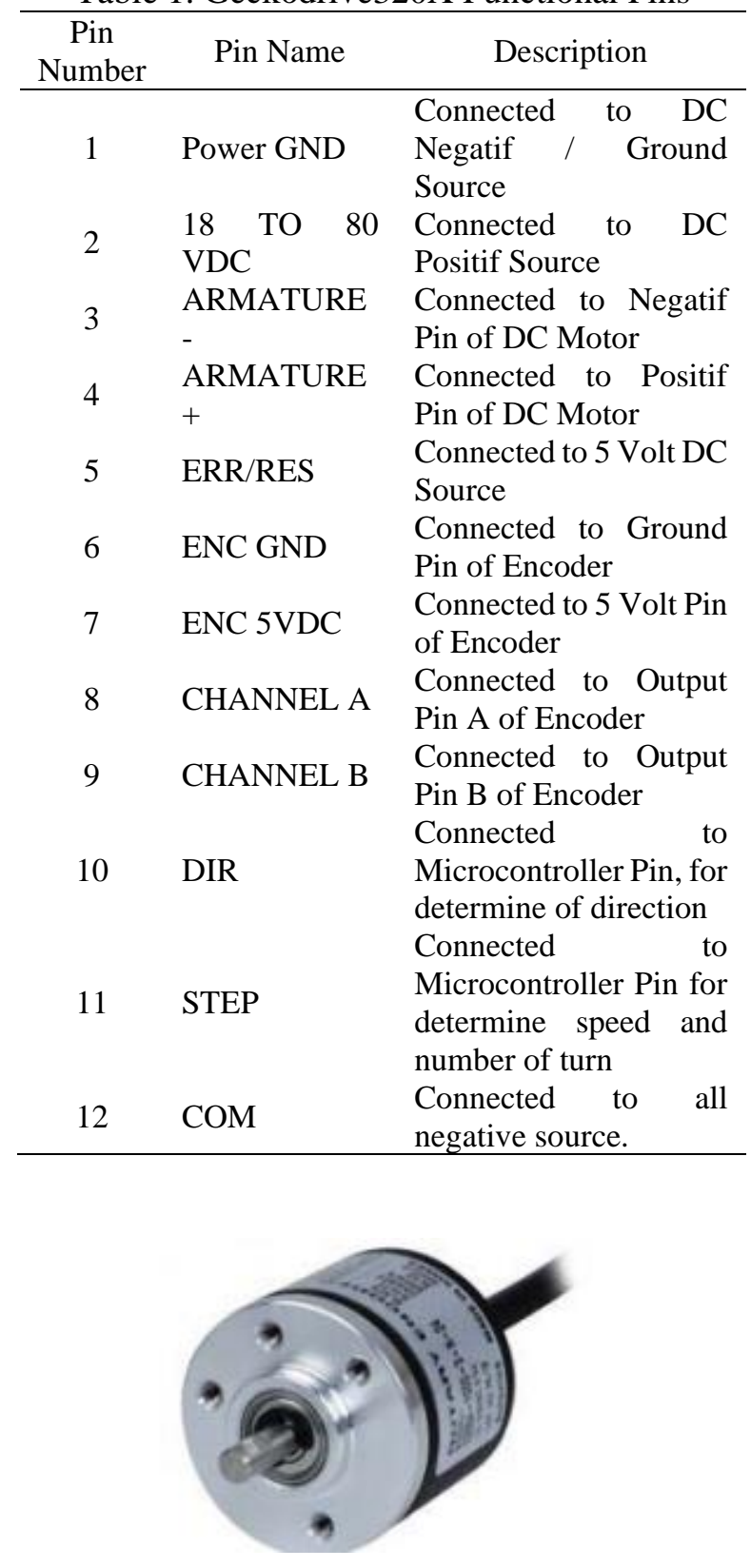

Figure 6. Encoder

Microcontroller, Geckodrive320x driver, encoder, and DC electric motor were assembled into a single control system. Figure 7 below shows the wiring diagram of the control component assembly. 


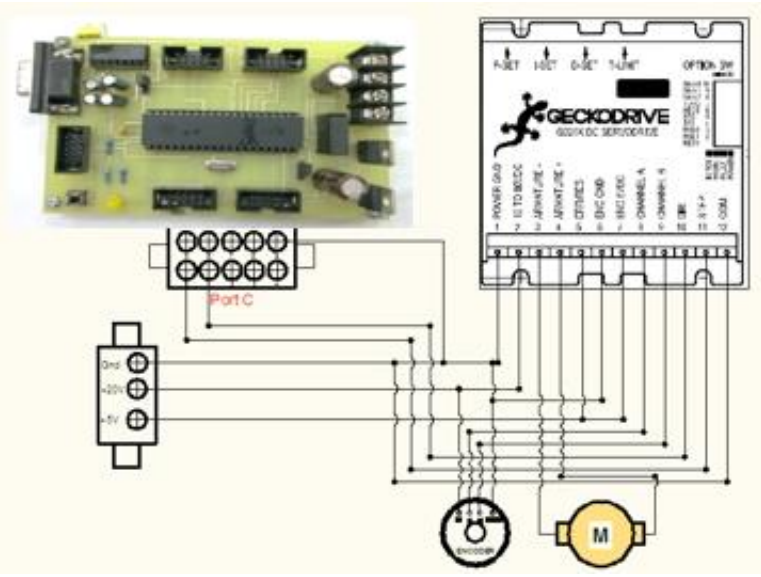

Figure 7. Wiring diagram of DC motor control system

The DC motor is connected to the slider shaft. See figure 8 .

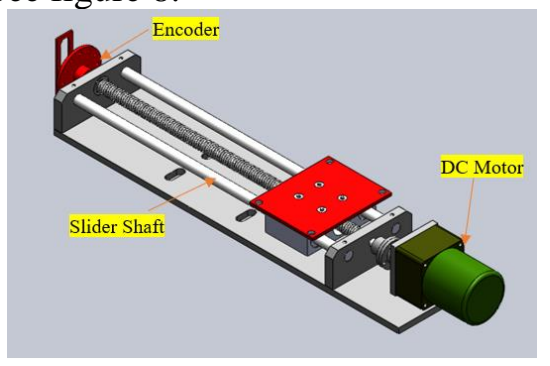

Figure 8. DC motor with slider after assembled

\section{RESULT AND DISCUSSION Testing The Number of Pulses}

After the control components were assembled, then the DC motor that has been equipped with a control system is tested. The first test is by giving a pulse of $360^{\circ}$ to Geckodrive $320 \mathrm{X}$, then the DC motor shaft rotation was observed for various values of Pin SW2 and SW3 settings. The encoder used in this test is an NPN Open Collector type encoder with 360 pulses per one revolution of the encoder shaft. Table 2 below shows the relations of pulse input with the shaft rotation.

Table 2. Relationship between the pulse input with the shaft rotation

\begin{tabular}{llc}
\hline SW2 & SW3 & Shaft Rotation $\left(^{(}\right)$ \\
\hline ON & ON & 90 \\
ON & OFF & 180 \\
OFF & ON & 450 \\
$O F F$ & OFF & 900 \\
\hline
\end{tabular}

The test results indicated that the number of revolutions of the DC motor shaft depends on the condition of the SW2 and SW3 Pin switches. In the condition $\mathrm{SW} 2=\mathrm{ON}$ and $\mathrm{SW} 3=\mathrm{ON}$ (multiplier factor 1) every 10 revolutions of the shaft requires four pulses. When $\mathrm{SW} 2=\mathrm{ON}$ and SW3 = OFF (multiplier factor 2), every 20 revolutions of the shaft requires four pulses. When SW2 $=$ OFF and SW3 = ON (multiplier factor 5) for every 50 shaft revolution requires four pulses. When SW2 = OFF and SW3 = OFF (multiplier factor 10) for every 100 shaft revolution requires four pulses. Table 3 below displays the details of the pin setting effect SW2 and SW3 conditions.

Table 3. Setting pin SW2 and SW3 conditions

\begin{tabular}{ccccc}
\hline $\begin{array}{c}\text { SW2 Pin } \\
\text { Switch } \\
\text { Condition }\end{array}$ & $\begin{array}{c}\text { SW3 Pin } \\
\text { Switch } \\
\text { Condition }\end{array}$ & $\begin{array}{c}\text { Multiplier } \\
\text { factor }\end{array}$ & $\begin{array}{c}\text { Pulses } \\
\text { needed }\end{array}$ & $\begin{array}{c}\text { Degree } \\
\text { of } \\
\text { Rotation }\end{array}$ \\
\hline ON & ON & 1 & 4 & 1 \\
ON & OFF & 2 & 4 & 2 \\
OFF & ON & 5 & 4 & 5 \\
OFF & OFF & 10 & 4 & 10 \\
\hline
\end{tabular}

\section{Testing the Motor Rotation}

After the relations between the number of pulses with the shaft rotation is known, the next test is to determine the maximum speed of the motor shaft that can be controlled by Geckodrive 320X in each condition SW2 and SW3. The test is carried out by providing a certain number of pulses with a rotating speed that varies until Geckodrive $320 \mathrm{X}$ is unable to position the motor shaft correctly. Table 4 below shows the test results of maximum shaft speed.

Table 4. Maximum shaft speed

\begin{tabular}{|c|c|c|}
\hline \multicolumn{2}{|c|}{ Switch Condition } & \multirow{2}{*}{$\begin{array}{l}\text { Rotation per minute } \\
(\text { rpm })\end{array}$} \\
\hline$S W 2$ & SW3 & \\
\hline$O N$ & $\mathrm{ON}$ & 462 \\
\hline ON & OFF & 521 \\
\hline$O F F$ & ON & 495 \\
\hline$O F F$ & OFF & 540 \\
\hline
\end{tabular}

The test results indicated that the maximum motor rotation speed for each switch condition is almost the same. The maximum speed is about $540 \mathrm{rpm}$. The smallest maximum speed value occurs in conditions SW2 $=\mathrm{ON}$ and SW3 $=\mathrm{ON}$, while the largest maximum speed value occurs in conditions SW2 $=$ OFF and SW3 $=$ OFF .

\section{Position Shift Testing}

The next test is to drive the servo motor that has been connected to the slider with a certain number 
of rotation in two directions for several times with different switch condition (SW2 and SW3). The distance from the start position to the end position of the slider then observed and measured. The difference in positioning of the start and end position after being driven by a servo motor with repeatedly then measured to see the maximum value of the deviation. Table 5 below displays test results of maximum deviation.

Table 5. Maximum deviation of slider

\begin{tabular}{cccc}
\multicolumn{4}{c}{ positioning } \\
\hline $\begin{array}{c}\text { SW2 Pin } \\
\text { Switch } \\
\text { Condition }\end{array}$ & $\begin{array}{c}\text { SW2 Pin } \\
\text { Switch } \\
\text { Condition }\end{array}$ & $\begin{array}{c}\text { Multiplier } \\
\text { factor }\end{array}$ & $\begin{array}{c}\text { Maximum } \\
\text { deviation }(\mathrm{mm})\end{array}$ \\
\hline$O N$ & ON & 1 & 0.05 \\
$O N$ & OFF & 2 & 0.04 \\
OFF & ON & 5 & 0.10 \\
OFF & OFF & 10 & 0.10 \\
\hline
\end{tabular}

The test results indicated that the maximum deviation value is related to the pulse multiplier factor. In the pulse multiplier conditions 1 and 2, the maximum deviation position of the slider is $0.05 \mathrm{~mm}$. In the pulse multiplier conditions 5 and 10 , the maximum deviation position of the slider is $0.10 \mathrm{~mm}$.

\section{CONCLUSION}

From the tests and analysts that have been conducted, the results obtained show the Geckodrive $320 \mathrm{X}$ module can be used to control a DC electric motor. The number of turns of the DC motor shaft depends on the condition of switches SW2 and SW3, by giving four pulses to Geckodrive320X module. The maximum speed of a DC motor can be controlled by Geckodrive $320 \mathrm{X}$ $540 \mathrm{rpm}$. And the maximum deviation of position on the slider shaft $0.01 \mathrm{~mm}$ in the condition of the multipliers factor 5 and 10.

\section{ACKNOWLEDGEMENTS}

The authors would like to thank the lecturer Dr. Ir. Tri Prakosa, M.Eng. and Dr.Eng. Ir. Agung Wibowo, M.T. for their support and guidance in the preparation of this paper. The authors also thank my wife, who always encouraged me to finish writing this scientific paper.

\section{REFERENCES}

Dharmawan, Hari Arief. 2017. Mikrokontroller: Konsep Dasar dan Praktis: Universitas Brawijaya Press.

Faruq, Mohamed Farid Bin Mohamed. 2008. "PID controller design for controlling DC motor speed using matlab application." Universiti Malaysia Pahang, Electrical \& Electronics Engineering.

Kurnia, Adam, Oetomo Oetomo, and Herry Sitepu. 2016. "Perancangan Antarmuka Instrumentasi dan Pengendalian Motor Servo Berbasis Octave." Jurnal Telematika no. 10 (1):5.

Lopatinsky, Edward, Daniel Schaefer, Savely Rosenfeld, and Lev Fedoseyev. 2006. Brushless DC electric motor. Google Patents.

Murphy, John, Francis McMullin, Michael Egan, and Michael Brosnan. 1987. Servomotor control systems. Google Patents.

Raditya, Bregas, Enrico Kartanadi, and Jimmy Linggarjati. 2011. "Pengendali Motor Servo DC Menggunakan PI untuk diimplementasikan pada Mesin CNC." Universitas Bina Nusantara.

Widiyanto, Wahyu, Wirawan Sumbodo, and Dony Hidayat Al Janan. 2012. "Analisis Perancangan dan Pembuatan Program PLC Pembacaan Encoder Pada Sistem Robot Record and Replay." Journal of Mechanical Engineering Learning no. 1 (1).

Zhou, Hongfu. 2008. DC servo motor PID control in mobile robots with embedded DSP. Paper read at 2008 International Conference on Intelligent Computation Technology and Automation (ICICTA). 